\title{
A note on copper prices
}

Between 1939 and 1953 the price of Zambian (then Rhodesian) copper was controlled by the British government. Thereafter, apart from interludes between $1955-57$ and $1964-66$, Zambian copper has been sold at prices determined daily on the London Metal Exchange (LME). The average daily price per ton in March 1970, just three months after the Zambian government had acquired a 5 I per cent ownership interest in the copper mines, was $\mathrm{KI}, 24 \mathrm{I}$ (£730). This was substantially higher than the estimated minimum price $\left(\mathrm{k} 75^{\circ}, £_{437}\right)$ required for Zambia to make compensation payments entirely out of her copper dividend earnings. However, by the end of 1970 the average price for the month of December had declined to $\mathrm{k} 740$. The average price for 1971 and 1972 was $k 75^{\circ}$ and $k 796$ per ton respectively. In 1973 political threats to the Zambian transport system, among other causes, resulted in a sharp rise of the price level to a record peak of more than $K 1,500$ (over $£_{1}, 000$ ) in November.

Zambia adopted the metric system under the Metric System Act of 1970. There are $2,205 \mathrm{lb}$ in one metric ton, compared with $2,240 \mathrm{lb}$ in one long ton, and $2,000 \mathrm{lb}$ in one short ton. 
